\title{
PENDIDIKAN AKHLAK
}

\author{
Jajang Abdul Rohman \\ E-Mail : Jajang.a.r.50@gmail.com \\ Universitas Islam Al-Ihya Kuningan
}

\begin{abstract}
ABSTRAK
Masalah Akhlak saat ini merupakan salah satu disintegrasi moral yang menjadi perhatian ditengah pesatnya perkembangan ilmu pengetahuan dan tekhnologi. Hal tersebut menjadi kesenjangan yang nampak dalam lingkungan Sosial.

Kualitas Akhlak yang ditampilkan Tentunya tidak hanya berpengaruh kepada pribadi dirinya sebagai pelaku utama, namun juga berpengaruh kepada segala sesuatu yang berhubungan dengan dirinya, nama baik keluarga, cara pandang orang lain terhadap keluarga dan lingkunganya, yang akan membawa pengaruh serta hasil dari perilakunya.
\end{abstract}

Kata Kunci : Akhlak, Pendidikan

\begin{abstract}
The current moral problem is one of the moral disintegration of concern amid the rapid development of science and technology. This is an apparent gap in the social environment.

The Moral Quality that is displayed Of course not only affects himself as the main actor, but also affects everything related to him, the good name of the family, the way other people perceive their family and environment, which will influence and the results of their behavior.
\end{abstract}

Keyword: Morals, Education 


\section{PENGANTAR}

Globalisasi adalah suatu hal yang tidak dapat dihadang oleh kekuatan apapun. Pada dasarnya globalisasi merupakan proses kemajuan yang melahirkan ketergantungan.

Sejalan dengan pesatnya perkembangan ilmu pengetahuan, keterampilan dan tekhnologi saat ini, sangat diperlukan pengembangan pendidikan yang disesuaikan dengan perkembangan zaman dengan menitikberatkan pada pengaruh yang dihasilkan baik berupa pengaruh positif maupun negatif.

Pendidikan yang menjadi bagian dari peradaban manusia yang harus mengalami perubahan dan perkembangan. Namun realita yang terjadi saat ini adalah sebuah pemandangan seperti mesin dimana guru sebagai subjek pentransfer ilmu pengetahuan, Tekhnologi dan siswa sebagai objek penerima ilmu pengetahuan dan Tekhnologi yang kemudian terlihat seperti sebuah tatanan mekanis.

Yang pada akhirnya mengenyampingkan permasalahan Moral. Moral didalam agama islam dikenal dengan sebutan Akhlak, baik akhlak terhadap guru, terhadap orangtua, terhadap teman, dan terhadap lingkunganya. Kondisi pendidikan seperti itu seharusnya mendorong kita untuk menyusun kembali cara pandang baru terhadap pendidikan yang tidak hanya berorientasi kepada pengetahuan (knowledge) dan keterampilan (skill) namun lebih penting dari itu adalah berorientasi pada nilai (value).

Subjek utama yang dapat merubah kualitas pendidikan yang merupakan figur manusia yang mempunyai tugas dan tanggung jawab tidak hanya dalam hal mengajarkan dan mentransfer ilmu, namun juga mendidik dan membimbing upaya menciptakan manusia yang tidak hanya memiliki kualitas pengetahuan, keterampilan namun juga memiliki kualitas akhlak yang baik, yang menjadi bekal hidupnya kelak.

Idealnya adalah semakin pesat perkembangan ilmu pengetahuan, keterampilan dan tekhnologi maka semakin tinggi juga moral dan kualitas akhlak sesuai dengan tujuan pendidikan.

Akhlak dalam pandangan Ibnu Miskawaih yakni sebuah tindakan hasil yang tanpa memerelukan berfikir terlebih dahulu, juga melalui tabiat semula ataupun melalui latihan dan kebiasaan. (Hasmah \& Zulfahmi, 2016)

Dari pandangan ibnu miskawaih dapat disimpulkan bahwa akhlak merupakan tindakan yang dihasilkan dari berbagai macam pola, baik tabiat bawaan yang terbentuk secara genesis, ataupun pola yang dibentuk melalui pendidikan, baik pendidikan yang dibentuk pada pendidikan formal, maupun pendidikan yang dibentuk pada lingkungan keluarga, yang kemudian menjadikan hasil sebuah adat dan kebiasaan yang ditimbulkan di lingkungan masyarakat sosial.

Maka penulis akan menyampaikan pendapat permasalahan tersebut dengan mengacu kepada Teori Zulfahmi 


\section{PEMBAHASAN}

Dalam ranah empiris, perilaku moral atau akhlak remaja di Indonesia merupakan masalah penting yang selalu mendapat perhatian dan menjadi sorotan. Krisis perkembangan akhlak nampak semakin buruk, Sejalan dengan perkembangan zaman dan kemajuan tekhnologi. Masalah tersebut menjadi semakin kompleks seperti pornografi,pergaulan bebas, narkoba, pencurian, tawuran, pembunuhan, dan gejolak lain dalam masyarakat. Terjadinya tindak kriminal yang dilakukan oleh anak-anak sekolah dan usia remaja merupakan realitas yang menunjukkan dekadensi moral dalam masyarakat kita yang disebabkan oleh tingkat pencerdasan kualitas akhlak yang rendah.

Masalah Akhlak adalah suatu masalah yang menjadi perhatian orang dimana saja, baik dalam masyarakat yang telah maju, maupun dalam masyarakat yang masih terbelakang. Karena kerusakan moral seseorang mengganggu ketentraman yang lain. Jika dalam sebuah masyarakat rusak akhlaknya maka rusak pula keadaan masyarakat itu.

Kualitas Akhlak yang ditampakkan Tentunya tidak hanya berpengaruh kepada pribadi dirinya sebagai pelaku utama, namun juga berpengaruh kepada segala sesuatu yang berhubungan dengan dirinya, nama baik keluarga, cara pandang orang lain terhadap keluarga dan lingkunganya, yang lambat laun akan merusak jati diri dan membawa pengaruh atau hasil dari perilakunya. Beberapa hal yang menjadi trend mode yang nampak adalah pola pergaulan, mode pakaian, lagu dan berbagai pola perilaku lain yang pada waktunya dapat merusak harkat, martabat dan jati diri bangsa itu sendiri. (Zamroni, 2011)

Zamroni menyebutkan bahwa yang nampak dan menjadi trend saat ini diantaranya mode pakaian yang mudah sekali ditemukan dimanapun dan kapanpun, baik lakilaki ataupun perempuan diusia remaja yang telah terkontaminasi pakaian ala barat yang cenderung menampakkan auratnya. tren lain lagu yang menjadi media hiburan dan media hafalan yang dianggap kekinian seolah mengisi pustaka ingatanya. Mereka lebih hafal lagu-lagu K-pop ala korea dan luar negeri lain daripada lagu daerah indonesia, lebih parah lagi tidak tahu, tidak hafal sama sekali lagu wajib Nasional bangsa Indonesia.

Ketidaksetaraan antara Pesatnya perkembangan ilmu pengetahuan, keterampilan dan tekhnologi saat ini dengan kualitas moral dan akhlak yang ditampakkan. Hal tersebut merupakan salah satu dari dampak positif dan dampak Negatif Globalisasi. Idealnya perkembangan ilmu pengetahuan tersebut sejalan dengan perkembangan moral atau akhlak.

Kesenjangan tersebut bisa timbul dan dipengaruhi oleh berbagai aspek.

Akhlak merupakan tindakan yang dihasilkan dari berbagai macam pola, baik tabiat bawaan yang terbentuk secara genesis, ataupun pola yang dibentuk melalui pendidikan, baik pendidikan yang dibentuk pada pendidikan formal, maupun pendidikan yang dibentuk pada lingkungan keluarga, yang kemudian menjadikan hasil sebuah adat dan kebiasaan yang ditimbulkan di lingkungan masyarakat sosial. 
Pendidikan formal berfungsi membantu peserta didik melalui ilmu pengetahuan, keterampilan, sikap, dan nilai yang memberikan kontribusi pada kepuasan serta output individu yang baik untuk lingkungan dan kehidupan sosial.

Pendidikan formal pada umumnya bermuara pada dua tujuan. Pertama, membantu generasi muda, peserta didik dalam memperoleh ilmu pengetahuan, keterampilan, sikap, akhlak dan nilai untuk kepuasaan hidup yang lebih baik.

Kedua, membantu individu mencapai kehidupan sosial sekaligus memberikan kontribusi kepada terciptanya masyarakat yang lebih baik didasarkan pada kepedulian dan perasaan kasih kepada sesama manusia dan makhluk hidup serta tidak mengganggu hak-hak orang lain untuk memenuhi nilai legitimasi dirinya.

Tujuan pendidikan selain meningkatkan ilmu pengetahuan, kecerdasan juga menanamkan akhlak mulia. (Fathiyah, 2013)

dikemukakan juga bahwa Gagasan Pendidikan Kebangsaan jelas menekankan pendidikan terpadu termasuk pendidikan akhlak yang sejalan dengan tujuan Pendidikan Islam. (Hafidz, 2012)

Pendidikan dikatakan berhasil bila output yang peserta didik mampu merealisasikan ilmu pengetahuan yang dimiliki serta merealisasikan dan menghasilkan nilai-nilai moral dan akhlak yang ditransmisikan, baik secara verbal maupun perilaku. Yang didalam islam dikenal dengan istilah berilmu amaliah dan beramal ilmiah

Kedua tujuan Pendidikan tersebut bersifat penting, saling berkaitan, meskipun tidak semua orang berilmu itu berakhlak, begitu juga tidak semua orang berakhlak pasti berilmu. Ilmu dan akhlak adalah dua entitas yang berbeda walaupun tetap memiliki hubungan yang sangat erat. Jika diibaratkan pada manusia, maka ilmu adalah laki-laki sementara akhlak adalah wanita. Ilmu adalah Bapak dan akhlak Ibunya.

Dalam tatanan Sosial sering kita menyaksikan orang awam, mereka tidak berilmu dan tidak berpendidikan tapi memiliki akhlak yang sangat baik. Mereka sangat tawadhu, sopan dan rendah hati. Orang-orang dengan tipe ini, memiliki beberapa kemungkinan.

Pertama, mereka mendapatkan didikan baik dari pendidikan formal, dari kedua orang tua dan lingkungan sekitarnya. Didikan itu dapat berupa nasihat ketika melakukan kesalahan dan juga teladan dalam keseharian. Hal-hal baik yang dilakukan oleh Guru, orang tua dan lingkungannya telah mempengaruhi aspek psikomotoriknya berupa peniruan-peniuran yang kemudian menjadi sebuah kebiasaan yang alami. Karenanya, terbentuklah karakter akhlak yang baik dan pengagungan terhadap norma-norma kesopanan yang berlaku.

Kedua, mereka menyadari keawamannya. Oleh karena itu, mereka cenderung menganggap orang lain lebih pintar, lebih alim dan berilmu. Dalam memandang orang lain, yang menjadi ukurannya adalah dirinya sendiri yang dianggap tidak tau apa-apa. Dari situ timbul sifat rendah hati. Tidak pernah menonjolkan diri diatas orang lain. Lebih banyak mendengar daripada berbicara, karena menganggap pendapat orang lain lebih bagus karena keluar dari orang-orang yang dianggapnya lebih pintar.Lebih sedikit bertindak daripada yang dilakukanya merupakan hal yang tidak baik, tidak sesuai norma, 
Kebiasaan tersebut yang menempatkan dirinya selalu di bawah daripada orang lain yang pada akhirnya membentuk budi pekerti dan Akhlak yang baik. Hanya saja, akhlak ini terkadang bersumber dari semacam sifat tidak percaya diri dalam bersosialisasi dengan orang lain. Namun demikian, merasa dirinya memiliki lebih banyak kekurangan dibanding orang lain tetaplah merupakan satu sifat yang baik yang harus dibiasakan saat ini dimana lebih banyak orang merasa lebih banyak kelebihan.

Sebaliknya sebagaimana kita sering menyaksikan orang awam dengan akhlak yang mengagumkan, kita juga sering bertemu orang-orang berilmu, berpendidikan namun tidak tercermin moral dan akhlak yang baik. Perilaku mereka tidak mencerminkan seseorang yang berpendidikan. Mereka berbicara dimana-mana, menjual dalil dan teori padahal kehidupan mereka jauh dari apa yang mereka ucapkan.

Mereka tidak memiliki empati dan kepedulian terhadap sesama karena merasa lebih memiliki banyak ilmu, lebih merasa Lebih menguasai ilmu yang pada esensinya orientasi mereka hanya kepentingan pribadi dan keluarganya, kurang menampakan akhlak yang baik terhadap orang lain kecuali yang dianggap dapat memenuhi kebutuhan dan kepentingannya, merasa paling benar, paling berilmu, paling layak, dan lain sebagainya. Perasaan semacam ini telah mengekalkan mereka dalam prinsipnya sambil terus merasa diri sebagai orang baik yang patut diteladani.

Gambaran tersebut memberikan penguatan bahwa akhlak terbagi menjadi dua bagian, pertama akhlak yang baik yang ditampilkan sesuai norma, agama dan adat yang berlaku. Kedua akhlak buruk disandarkan kepada perbuatan orang tidak sesuai denagn norma, agama, adat yang berlaku. (Imam, 2013)

Fenomena tersebut merupakan gambaran yang paling nyata yang dapat diambil simpul mengenai keterkaitan antara ilmu dan akhlak.sebagaimana akhlak adalah suatu ciri kehidupan manusia karena manusia merupakan makhluk sosial yang terlibat langsung pada kehidupan dan interaksi sosial. (Collste, 2012)

Dari uraian tersebut diatas, peran pendidikan sangat Penting.

Dalam pendidikan formal guru berposisi sebagi sentral. Guru adalah faktor penting yang mempengaruhi proses serta hasil pembelajaran siswa dan mempengaruhi hasil dan keahlian peserta didik. (Imam, 2013)

Namun harus difahami bahwa guru tidak hanya sebagai mediator penyampai sebuah ilmu dan pengetahuan, Tapi Pendidik yang juga harus berperan sebagai pengontrol, pembentuk, pembimbing pengubah kualitas akhlaknya. Sebagai mana teori Taksonomi Bloom bahwa pendidikan menekankan kepada aspek Kognitif, Afektif, dan psikomotor, sebelum dijalankan sebagai rujukan hasil pendidikan kepada siswa maka seharusnya diterapkan terlebih dahulu diterapkan kepada pihak warga sekolah terutama Guru Selain cerdas secara kognitif, juga diharuskan sadar secara afektif, serta mulia secara psikomotorik.

Memberikan pengajaran dan menyampaikan pendidikan tidak hanya materi dan ilmu melalui ucapan, namun harus menampilkan keluasan hati yang teguh, sabar, rendah hati serta mampu mengontrol suasana dan emosi hatinya, serta memberi pengajaran melalui contoh dalam tindakan yang mulia, karena ketiga aspek itulah yang dapat mempengaruhi keadaan dan kualitas akhlak siswanya.tidak hanya 
berlaku untuk semua guru, namun juga harus menjadi sebuah prinsip kerja dantara Kepala Sekolah, Pendidik dan lainya. Terlebih jika kita berposisi sebagai Pendidik di Lingkungan Formal berbasis agama. Pendidikan Islam menekankan kemahiran penguasaan dan penghayatan ilmu serta melahirkan insan yang bertakwa.

(Azmi, 2012)

Maka jelas bagi pendidik yang berada pada lembaga formal berbasis agama, tidak hanya kognitif, afektif, dan psikomotorik saja, namun kualitas manusia yang bertaqwa dengan menampilkan nilai-nilai keagamaan dan kualitas keagamaanya.

Tetapi tidak sampai disitu, Guru dan Lembaga pendidikan bukanlah satu-satunya yang memberikan pengaruh kepada kualitas akhlak seseorang, disisi lain peran lingkungan keluarga juga penting sebagai penentu akhlak, karena interaksi lebih sering terjadi di lingkungan keluarga.

Dalam sudut pandang pedagogis lingkungan keluarga adalah lingkungan primer dimana pembentukan sebuah proses pengetahuan dan moral bisa terjadi dengan tidak terstruktur namun pelaksanaanya tidak terbatas waktu.

Peran pendidikan akhlak dalam keluarga adalah usaha bimbingan, pengarahan dan atau latihan dengan membiasakan anak didik agar terbiasa melakukan perbuatan-perbuatan terpuji dan menjauhi perbuatanperbuatan tercela, yang diarahkan kepada pembentukan kepribadian anak, sehingga anak memperoleh sikap dan pengetahuan dari pengalamannya sehari-hari baik secara sadar atau tidak diperoleh dari keluarga.

Pendidikan akhlak dalam keluarga adalah dasar dari pembentukan watak dan kepribadian. Watak itu terbentuk melalui proses pembentukan kebiasaan dan pengertian, serta merupakan perpaduan yang meliputi bakat, pendidikan, pengalaman dan alam sekelilingnya, yang menyatakan diri dalam segala rupa tingkah laku.

Dapat disimpulkan bahwa antara sekolah dan lingkungan keluarga adalah bagian yang tidak dapat dipisahkan dalam proses pembentukkan Akhlak, maka harus dibangun relasi komunikasi yang baik antara keduanya agar dapat menghasilkan kualitas tujuan pendidikan. Untuk itu, perlu usaha membangun persamaan persepsi. Penting setiap stakeholder memahami tujuan pendidikan yang akan dicapai. Usaha membangun persamaan persepsi dan memahami tujuan pendidikan di sekolah dapat dilakukan dengan berbagai cara. Salah satunya adalah dengan mengadakan pertemuan antara orang tua dan sekolah secara berkala. Misalnya bisa dilakukan dengan mengadakan acara seminar parenting, yang diagendakan khusus untuk membangun persamaan pandangan, Persamaan persepsi tentang tujuan sekolah, rencana tahunan, semester yang di dalamnya orang tua dan guru duduk bersama untuk menyamakan berbagai pemahaman dan usaha. Bahwa dalam pembentukan ahklah tidak hanya guru yang memberikan teladan yang baik disekolah, namun juga mendorong orang tua agar menjadi teladan yang baik dirumah.

Dengan demikian iklim di rumah dan di sekolah tidak terjadi diferensiasi yang bertolak belakang. Ratlife dan Ponte menyebut ini dengan family-school partnerships dimana orang tua menghargai kemitraan keluarga sekolah sebagai sesuatu yang penting, mendukung pembelajaran anak dan ingin mengetahui pengalaman anak-anak di sekolah. (Ratliffe \& Ponte, 2018) 
Namun tidak sampai disitu, relasi tersebut harus berlanjut, pertemuan guru dengan menyampaikan evaluasi, selanjutnya bisa juga dengan mengadakan persiapan kegiatan-kegiatan diluar seperti home visit, family gathering atau camping jika ada. Ini menjadi kegiatan penting agar orang tua dan guru dapat berkolaborasi dalam menacapai tujuan pembelajaran. Intensitas pertemuan yang demikian menunjukkan banyak hal yang perlu peran sekolah-keluarga secara bersama-sama. Bahkan di Virginia Amerika, mereka mengadakan kegiatan pertemuan guru dan orang tua setiap bulan dan mengadakan konferensi dua kali setahun.

(Kayser, 2017)

Untuk itu, sejak awal seharusnya sekolah didukung oleh pemerintah dalam proses membangun persamaan persepsi antara orang tua dan guru. Bahkan diluar Indonesia ini sudah menjadi sebuah komitmen sejak 50 tahun terakhir. Di Swedia sudah memikirkan bagaimana memanfaatkan hubungan sekolah-keluarga untuk ikut mempromosikan masalah kesehatan karena dinilai lebih efektif.

(Bergnehr, 2015) 
Pembentukan, dan perkembangan Akhlak menjadi penting dan tidak hanya menjadi Tanggung Jawab Lembaga Formal Pendidikan disekolah yang terbatas waktu, Guru yang Menampilkan Kepribadian dan Teladan yang baik, Tetapi diperlukan pula Peran Lingkungan Keluarga yang merupakan lingkungan primer dimana pembentukan sebuah proses pengetahuan dan Akhlak bisa terjadi dengan tidak terstruktur namun pelaksanaanya tidak terbatas waktu agar tidak terjadi diferensiasi. sekolah dan lingkungan keluarga adalah bagian yang tidak dapat dipisahkan dalam proses pembentukkan Akhlak, maka harus dibangun relasi komunikasi yang baik antara keduanya agar dapat menghasilkan kualitas tujuan pendidikan. Untuk itu, perlu usaha membangun persamaan persepsi. Sangat Penting setiap pihak, baik pihak Sekolah dan Orangtua memahami tujuan pendidikan yang akan dicapai. Salah satu contoh adalah dengan mengadakan pertemuan antara orang tua dan sekolah secara berkala, dan berkelanjutan. Sehingga terjalin Kolaborasi untuk mencapai tujuan Pendidikan dan Pembelajaran. 


\section{REFERENSI}

Azmi, K. (2012). Pendidikan Islam: Kaedah Pengajaran dan Pembelajaran. Skudai : Universiti Teknologi.

Bergnehr, D. (2015). "Advancing home-school relations through parent support?". Ethnography and Education .

Collste, G. (2012). Applied and Profesional Ethics. The Asian Journal of Humanities.

Fathiyah. (2013). Penerapan Elemen Ilmu Pendidikan Agama Islam Oleh Guru Pendidikan Agama Islam. Wacana Pendidikan Islam.

Hafidz, A. (2012). Memperkasa Jati Diri Muslim Menerusi Pendidikan Islam Dalam Pengajaran Akhlak. Jurnal Hadhari.

Hasmah, W., \& Zulfahmi. (2016). Akhlak Guru dalam Pengajaran dan Pembelajaran Pendidikan Islam Teacher's Good Behaviour in Teaching and Learning the Islamic Education. Akademika.

Imam, A. (2013). The Qur'anic Approach to the Inculcation of Moral Values: Patterns for Teacher Education. International Jurnal of Qur'anic Research.

Kayser, A. A. (2017). "Family Values: an Immigrant Teachers's Stories". Educational.

Ratliffe, K., \& Ponte, E. (2018). "Parent Perspectives on Developing Effective Partnerships in Hawai 'i”. Community Journal.

Zamroni. (2011). Dinamika Peningkatan Mutu. Yogyakarta: Gavin Kalam Utama. 